\title{
Monthly rainfall forecast of Bangladesh using autoregressive integrated moving average method
}

\author{
Ishtiak Mahmud $^{1^{\dagger}}$, Sheikh Hefzul Bari ${ }^{2}$, M. Tauhid Ur Rahman ${ }^{3}$ \\ ${ }^{1}$ Department of Civil and Environmental Engineering, Shahjalal University of Science and Technology, Sylhet-3114, Bangladesh \\ ${ }^{2}$ Department of Civil Engineering, Leading University, Sylhet-3100, Bangladesh \\ ${ }^{3}$ Department of Civil Engineering, Military Institute of Science and Technology, Dhaka-1216, Bangladesh
}

\begin{abstract}
Rainfall is one of the most important phenomena of the natural system. In Bangladesh, agriculture largely depends on the intensity and variability of rainfall. Therefore, an early indication of possible rainfall can help to solve several problems related to agriculture, climate change and natural hazards like flood and drought. Rainfall forecasting could play a significant role in the planning and management of water resource systems also. In this study, univariate Seasonal Autoregressive Integrated Moving Average (SARIMA) model was used to forecast monthly rainfall for twelve months lead-time for thirty rainfall stations of Bangladesh. The best SARIMA model was chosen based on the RMSE and normalized BIC criteria. A validation check for each station was performed on residual series. Residuals were found white noise at almost all stations. Besides, lack of fit test and normalized BIC confirms all the models were fitted satisfactorily. The predicted results from the selected models were compared with the observed data to determine prediction precision. We found that selected models predicted monthly rainfall with a reasonable accuracy. Therefore, year-long rainfall can be forecasted using these models.
\end{abstract}

Keywords: ARIMA model, Bangladesh, Forecast, Monthly rainfall, Time series

\section{Introduction}

Prediction of rainfall is tough due to its non-linear pattern and a large variation in intensity. Till today, numerous techniques have been used to predict rainfall. Among them, Autoregressive Integrated Moving Average (ARIMA) modeling, introduced by Box and Jenkins [1] is an effective method. The Box-Jenkins Seasonal ARIMA (SARIMA) model has several advantages over other models, particularly over exponential smoothing and neural network, due to its forecasting capability and richer information on time-related changes [2]. ARIMA model consider the serial correlation which is the most important characteristic of time series data. ARIMA model also provides a systematic option to identify a better model. Another advantage of ARIMA model is that the model uses less parameter to describe a time series.

Rahman et al. [3] used a comparative study of ANFIS and ARIMA model for the weather forecast in Dhaka city and found that ARIMA model performs better than ANFIS. Johnson and Montgomery [4] consider Box and Jenkins ARIMA method as possibly the most precise method for forecasting of time series data. According to Dizon [5], the Box-Jenkins methodology is particularly suited for the development of a model that exhibit strong seasonal behavior. Momani [6] successfully used ARIMA model for predicting rainfall trend of Jordan.

In Bangladesh, ARIMA modeling has been applied to few of the available rainfall stations. Mohsin et al. [7] used ARIMA model to forecast the rainfall of Dhaka city. Rainfall forecast for Sylhet station has been done by Bari et al. [8]. They have concluded that ARIMA model was adequate in predicting monthly rainfall for these stations. However, rainfall forecast for all over Bangladesh has not been done yet. In this paper, Box-Jenkins approach has been used to build seasonal ARIMA model of monthly rainfall data of various stations in Bangladesh. Development of a reliable forecasting model of rainfall series will be helpful to mitigate natural hazards like flood and drought. A precise year-long prediction will also help in agricultural water use planning. The forecasted data series will also reveal likely future rainfall trend.
This is an Open Access article distributed under the terms of the Creative Commons Attribution Non-Commercial License (http://creativecommons.org/licenses/by-nc/3.0/) which permits unrestricted non-commercial use, distribution, and reproduction in any medium, provided the original work is properly cited.
Received May 20, 2016 Accepted November 24, 2016

${ }^{\dagger}$ Corresponding author

Email: ishtiak006@gmail.com

Tel: +88-01791327282

Copyright (C) 2017 Korean Society of Environmental Engineers 


\section{Materials and Methods}

Bangladesh is a low-lying, riverine country with a largely wet jungle coastline. It extends from $20^{\circ} 34^{\prime}$ to $26^{\circ} 38^{\prime}$ north latitude and $88^{\circ} 01^{\prime}$ to $92^{\circ} 41^{\prime}$ east longitude [9]. The country has a sub-tropical humid climate characterized by extensive seasonal variations in rainfall, moderately warm temperature and high humidity [9]. Rainfall in Bangladesh varies from 1,400 $\mathrm{mm}$ in the west to more than $4,300 \mathrm{~mm}$ in the east. About $75 \%$ rainfall occurs during monsoon in Bangladesh [10]. A more detail discussion about the climate of Bangladesh is given by Rashid [9].

\subsection{Data Collection and Quality Control}

Rainfall data for 35 stations were collected from Bangladesh Agricultural Research Council (BARC). BARC collect weather data from Bangladesh Meteorological Department (BMD).

Quality control of data is an essential step before the calculation of indices because erroneous outliers can mislead the index calculation [11]. The key purpose of the quality control procedure was to identify errors in data processing, such as errors in manual keying [12]. As a first step, missing values were screened. Stations, containing more than $2 \%$ missing value were excluded from the modeling. Other checks such as identification of consecutive month with the same amount of rainfall along the year, the precipitation

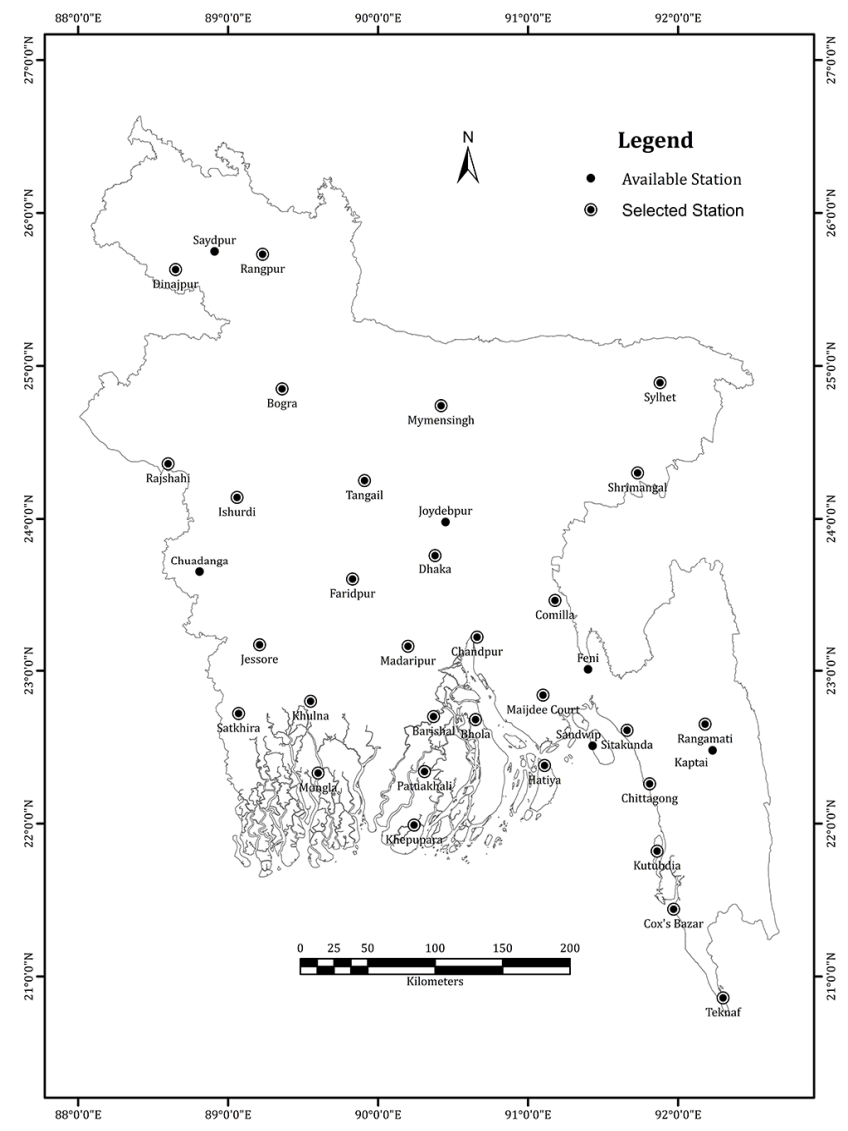

Fig. 1. Study area. value below $0 \mathrm{~mm}$, winter rainfall more than average rainfall and monsoon rainfall below the threshold limit were also carried out [10]. After checking these, thirty stations having long-term data (more than 20 y) up to the year 2013 and passing the above tests were used in the present study. Locations of the stations are shown in Fig. 1.

The homogeneity of the data series was identified using Standard Normal Homogeneity test [13], Von Neumann Ratio test [14], Buishand Range test [15] and Pettitt test [16]. The rainfall data sets of all the stations were found homogenous except for Shrimangal station. There was a breakpoint for Srimangal at 1961. Therefore, rainfall data from 1961 to 2013 was used for this station.

\subsection{The ARIMA Model}

Seasonal ARIMA model, proposed by Box and Jenkins [1] was used for model building and forecasting monthly rainfall. Seasonal ARIMA model can be labeled as ARIMA (p, d, q) * $(P, D, Q)_{s}$ where $(p, d, q)$ is the nonseasonal part and $(P, D, Q)_{s}$ is the seasonal part of the model which could be written as:

$$
\phi_{p}(B) \Phi_{p}\left(B^{s}\right) \nabla^{d} \nabla_{s}^{D} z_{t}=\theta_{q}(B) \Theta_{Q}\left(B^{S}\right) a_{t}
$$

Where, $p=$ non-seasonal Auto Regressive (AR) order, $d=$ non-seasonal differencing, $q=$ non-seasonal Moving Average (MA) order, $P=$ seasonal AR order, $D=$ seasonal differencing, $Q=$ seasonal MA order, and $S=$ length of the season.

Building an ARIMA model consists of four systematic stages (identification, estimation, diagnostic check and application or forecast). The identification phase involves the improvement of the stationarity and normality of the data. At this stage, the general form of the model is estimated. Model parameters are calculated using the method of maximum likelihood at estimation stage. The diagnostic checks are performed to reveal the possible inadequacies and to select the best model. Finally, the forecasting of the rainfall time series is done.

\section{Results and Discussion}

\subsection{Model Identification}

The identification stage involves checking the stationarity and normality of time series data. Initially, the data series were analyzed to check if the data are stationary and if there are any seasonality exists. The temporal correlation structure of the monthly time series was identified using Autocorrelation (ACF) and Partial Autocorrelation (PACF) Function [17]. Inspecting the time series plot, ACF, and PACF a clear seasonality of twelve months cycle was detected. Therefore, seasonal differencing of an appropriate order was done to remove seasonality and to achieve stationarity of data. A first order seasonal differencing was adequate to achieve stationarity for all the stations.

For example, time series plot of Rajshahi station is shown with ACF and PACF plots in Fig. 2. The sine-wave formation of ACF indicates that the data is seasonal. After a first order seasonal differencing ACF and PACF plot (Fig. 3) shows that the series is stationary. The ACF and PACF of the differenced series show 

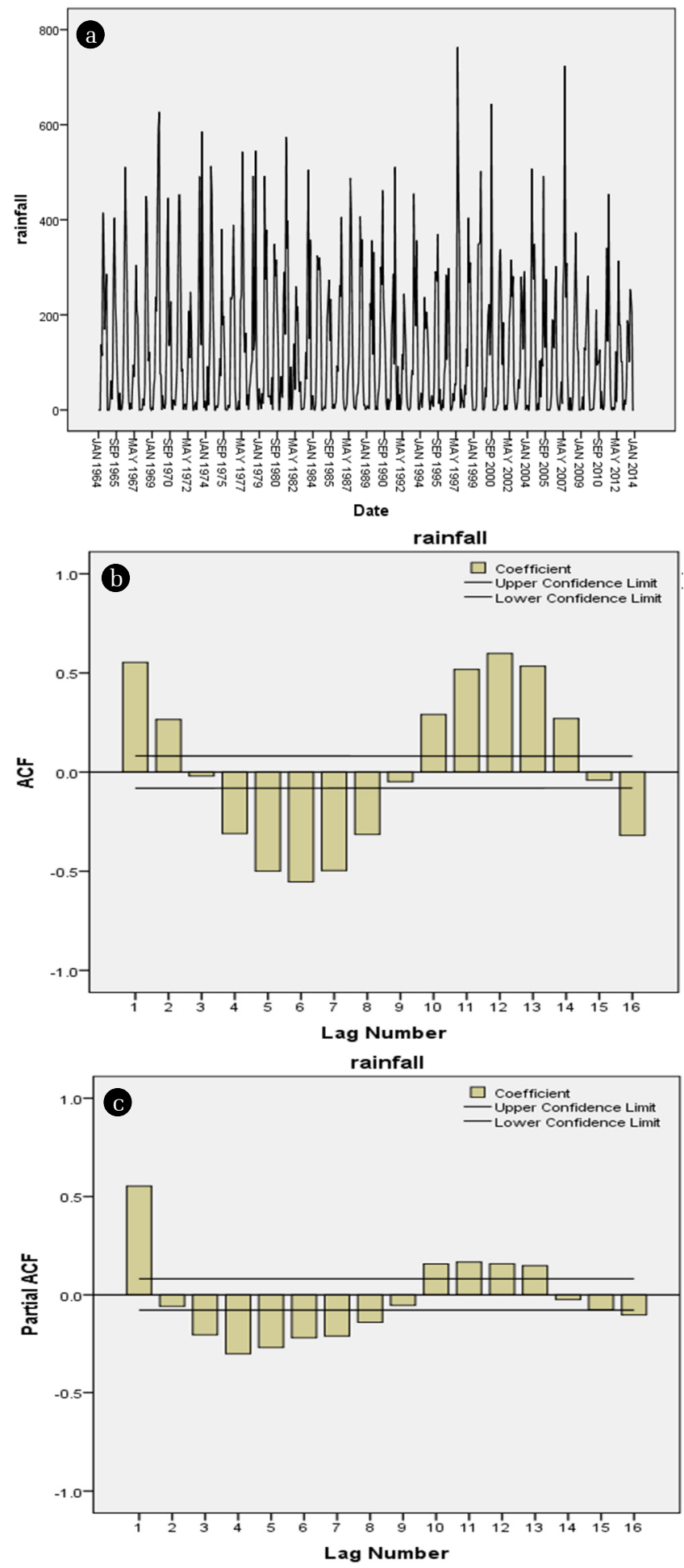

Fig. 2. Time series (a), ACF (b) and PACF (c) plot of rainfall for Rajshahi station.

no significant spikes indicating simplest Seasonal ARIMA process. However, the model could be a combination of both AR and MA process. The ACF and PACF plot direct a possible SARIMA model
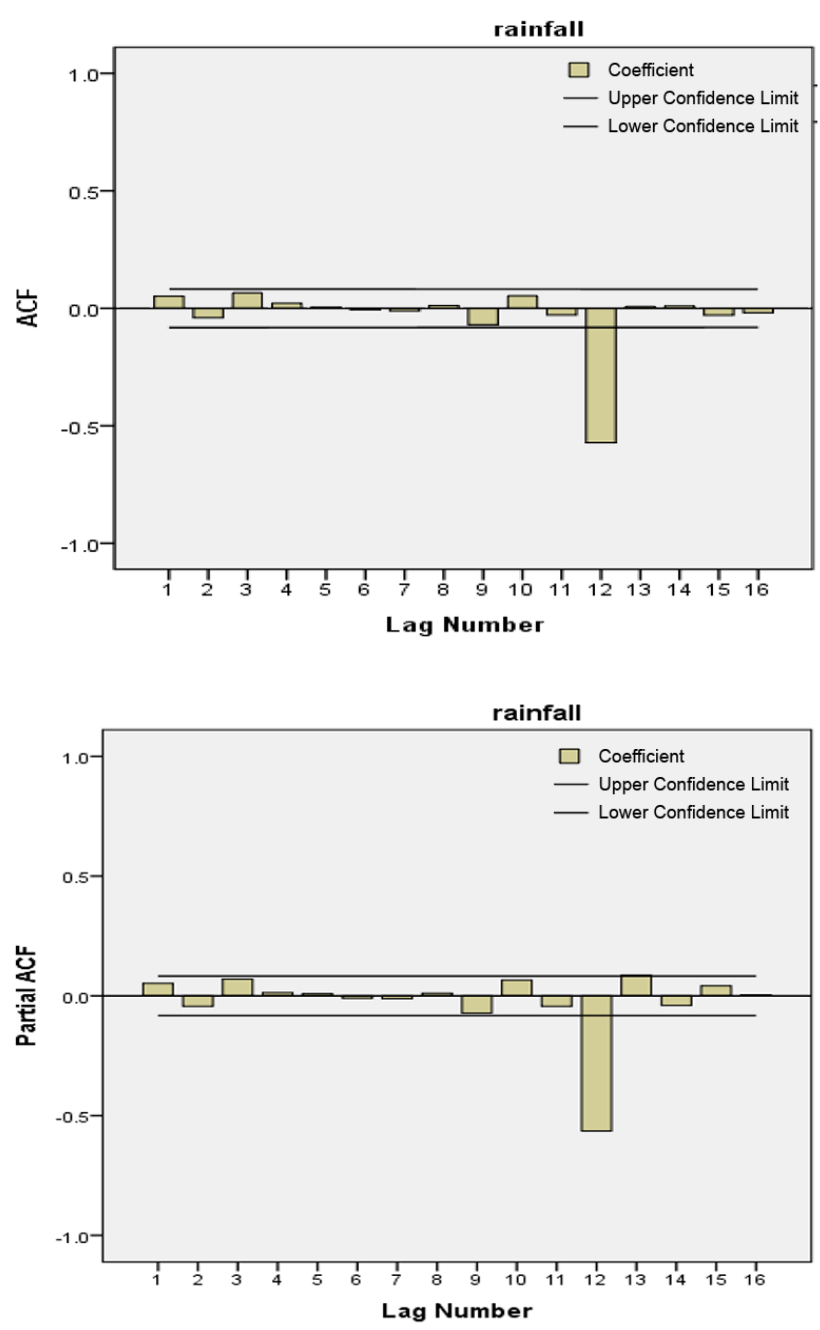

Fig. 3. ACF and PACF plot of transformed series (Rajshahi).

with $\mathrm{P}=0-2$ and $\mathrm{Q}=0-2$. All the possible combinations using several $\mathrm{P}$ and $\mathrm{Q}$ ranging from zero to two were examined to determine the best ARIMA model from the nominee models. The model that gives the best combination of minimum RMSE, maximum R-squared, and least Normalized BIC was selected as the best fit model.

\subsection{Parameter Estimation}

Primary estimation of the parameters was done from AR and MA at the identification stage. This preliminary evaluation was then used to compute the final parameter by the procedure described by Box and Jenkins (1976) [1]. The value of the parameters, standard error (SE), t-ratio, and p-values for each station are shown in Table 1. The standard error calculated for the relevant parameter is small compared to the parameter values. Therefore, the parameters are statistically significant [2].

\subsection{Diagnostic Check}

The diagnostic check was done once the model parameters were 
Table 1. Statistical Analysis of Parameter

\begin{tabular}{|c|c|c|c|c|c|c|c|}
\hline Station & Model & Parameter & & Estimate & SE & $\mathbf{t}$ & Significance (p value) \\
\hline Barishal & $\operatorname{ARIMA}(0,0,0)(0,1,1)$ & Q & lag1 & 0.862 & 0.032 & 26.646 & 0 \\
\hline Bhola & $\operatorname{ARIMA}(0,0,0)(0,1,1)$ & Q & lag1 & 0.959 & 0.053 & 18.099 & 0 \\
\hline Bogra & $\operatorname{ARIMA}(0,0,0)(0,1,1)$ & Q & lag1 & 0.969 & 0.013 & 72.797 & 0 \\
\hline Chandpur & $\operatorname{ARIMA}(0,0,0)(0,1,1)$ & Q & lag1 & 0.97 & 0.027 & 35.299 & 0 \\
\hline Chittagong & $\operatorname{ARIMA}(0,0,0)(0,1,1)$ & Q & lag1 & 0.967 & 0.027 & 36.259 & 0 \\
\hline Comilla & $\operatorname{ARIMA}(0,0,0)(0,1,1)$ & Q & lag1 & 0.972 & 0.028 & 34.524 & 0 \\
\hline Cox's Bazar & $\operatorname{ARIMA}(0,0,0)(0,1,1)$ & Q & lag1 & 0.919 & 0.021 & 43.526 & 0 \\
\hline \multirow{3}{*}{ Dhaka } & \multirow{3}{*}{$\operatorname{ARIMA}(0,0,0)(1,1,2)$} & $\mathrm{P}$ & lag1 & -0.573 & 0.368 & -1.558 & 0.12 \\
\hline & & \multirow{2}{*}{ Q } & lag1 & 0.485 & 0.387 & 1.254 & 0.21 \\
\hline & & & lag2 & 0.515 & 0.386 & 1.334 & 0.183 \\
\hline Dinajpur & $\operatorname{ARIMA}(0,0,0)(0,1,1)$ & Q & lag1 & 0.929 & 0.02 & 46.887 & 0 \\
\hline Faridpur & $\operatorname{ARIMA}(0,0,0)(0,1,1)$ & Q & lag1 & 0.961 & 0.03 & 31.633 & 0 \\
\hline \multirow{2}{*}{ Hatiya } & \multirow{2}{*}{$\operatorname{ARIMA}(0,0,1)(0,1,1)$} & q & lag1 & -0.158 & 0.04 & -3.906 & 0 \\
\hline & & Q & lag1 & 0.939 & 0.022 & 42.319 & 0 \\
\hline Ishurdi & $\operatorname{ARIMA}(0,0,0)(0,1,1)$ & Q & lag1 & 0.991 & 0.042 & 23.656 & 0 \\
\hline \multirow{2}{*}{ Jessore } & \multirow{2}{*}{$\operatorname{ARIMA}(0,0,0)(0,1,2)$} & \multirow{2}{*}{ Q } & lag1 & 0.979 & 0.037 & 26.42 & 0 \\
\hline & & & lag2 & -0.044 & 0.037 & -1.191 & 0.234 \\
\hline \multirow{2}{*}{ Khepupara } & \multirow{2}{*}{$\operatorname{ARIMA}(0,0,1)(0,1,1)$} & $q$ & lag1 & 0.145 & 0.046 & 3.176 & 0.002 \\
\hline & & Q & lag1 & 0.921 & 0.028 & 33.039 & 0 \\
\hline Khulna & $\operatorname{ARIMA}(0,0,0)(0,1,1)$ & Q & lag1 & 0.955 & 0.02 & 47.747 & 0 \\
\hline Kutubdia & $\operatorname{ARIMA}(0,0,0)(0,1,1)$ & Q & lag1 & 0.929 & 0.043 & 21.66 & 0 \\
\hline Madaripur & $\operatorname{ARIMA}(0,0,0)(0,1,1)$ & Q & lag1 & 0.926 & 0.034 & 27.165 & 0 \\
\hline Maijdeecourt & $\operatorname{ARIMA}(0,0,0)(0,1,1)$ & Q & lag1 & 0.971 & 0.048 & 20.361 & 0 \\
\hline \multirow{2}{*}{ Mongla } & \multirow{2}{*}{$\operatorname{ARIMA}(0,0,0)(0,1,2)$} & \multirow{2}{*}{ Q } & lag1 & 0.96 & 0.062 & 15.548 & 0 \\
\hline & & & lag2 & -0.079 & 0.062 & -1.272 & 0.205 \\
\hline Mymensingh & $\operatorname{ARIMA}(0,0,0)(0,1,1)$ & Q & lag1 & 0.962 & 0.015 & 64.464 & 0 \\
\hline Patuakhali & $\operatorname{ARIMA}(0,0,0)(0,1,1)$ & Q & lag1 & 0.939 & 0.029 & 32.123 & 0 \\
\hline \multirow{2}{*}{ Rajshahi } & \multirow{2}{*}{ ARIMA(0,0,0)(1,1,1) } & $\mathrm{P}$ & lag1 & -0.201 & 0.041 & -4.853 & 0 \\
\hline & & Q & lag1 & 0.986 & 0.033 & 29.441 & 0 \\
\hline \multirow{2}{*}{ Rangamati } & \multirow{2}{*}{ ARIMA $(0,0,0)(1,1,1)$} & $\mathrm{P}$ & lag1 & -0.089 & 0.043 & -2.079 & 0.038 \\
\hline & & Q & lag1 & 0.972 & 0.031 & 31.371 & 0 \\
\hline Rangpur & $\operatorname{ARIMA}(0,0,0)(0,1,1)$ & Q & lag1 & 0.945 & 0.02 & 47.163 & 0 \\
\hline Satkhira & $\operatorname{ARIMA}(0,0,0)(0,1,1)$ & Q & lag1 & 0.983 & 0.039 & 25.329 & 0 \\
\hline Shrimangal & $\operatorname{ARIMA}(0,0,0)(0,1,2)$ & Q & lag1 & 0.948 & 0.022 & 43.083 & 0 \\
\hline Sitakunda & $\operatorname{ARIMA}(0,0,0)(0,1,1)$ & Q & lag1 & 0.9 & 0.036 & 24.749 & 0 \\
\hline \multirow{2}{*}{ Sylhet } & \multirow{2}{*}{$\operatorname{ARIMA}(0,0,0)(0,1,2)$} & \multirow{2}{*}{ Q } & lag1 & 1.098 & 0.273 & 4.023 & 0 \\
\hline & & & lag2 & -0.102 & 0.045 & -2.243 & 0.025 \\
\hline Tangail & $\operatorname{ARIMA}(0,0,0)(0,1,1)$ & Q & lag1 & 0.957 & 0.082 & 11.672 & 0 \\
\hline Teknaf & $\operatorname{ARIMA}(0,0,0)(0,1,1)$ & Q & lag1 & 0.917 & 0.03 & 30.931 & 0 \\
\hline
\end{tabular}

calculated to verify the adequacy of the prediction. The residuals should be white noise for a useful forecasting model. Several tests carried out on residuals are described below:

\subsubsection{ACF and PACF of residuals}

The majority of the ACF and PACF values of residuals lie within the confidence limit which indicates no significant correlation among them. Illustration of the ACF and PACF of residuals for rainfall series of Rajshahi station are given in Fig. 4. The figure shows that the residuals are white noise.

\subsubsection{Histogram of residual}

Histogram of residuals of rainfall series of Rajshahi station (Fig. 4(b)) shows that the residuals are normally distributed. Remaining series also exhibit similar result.

\subsubsection{Normal probability of residuals}

The cumulative distribution of the residuals data usually appears 

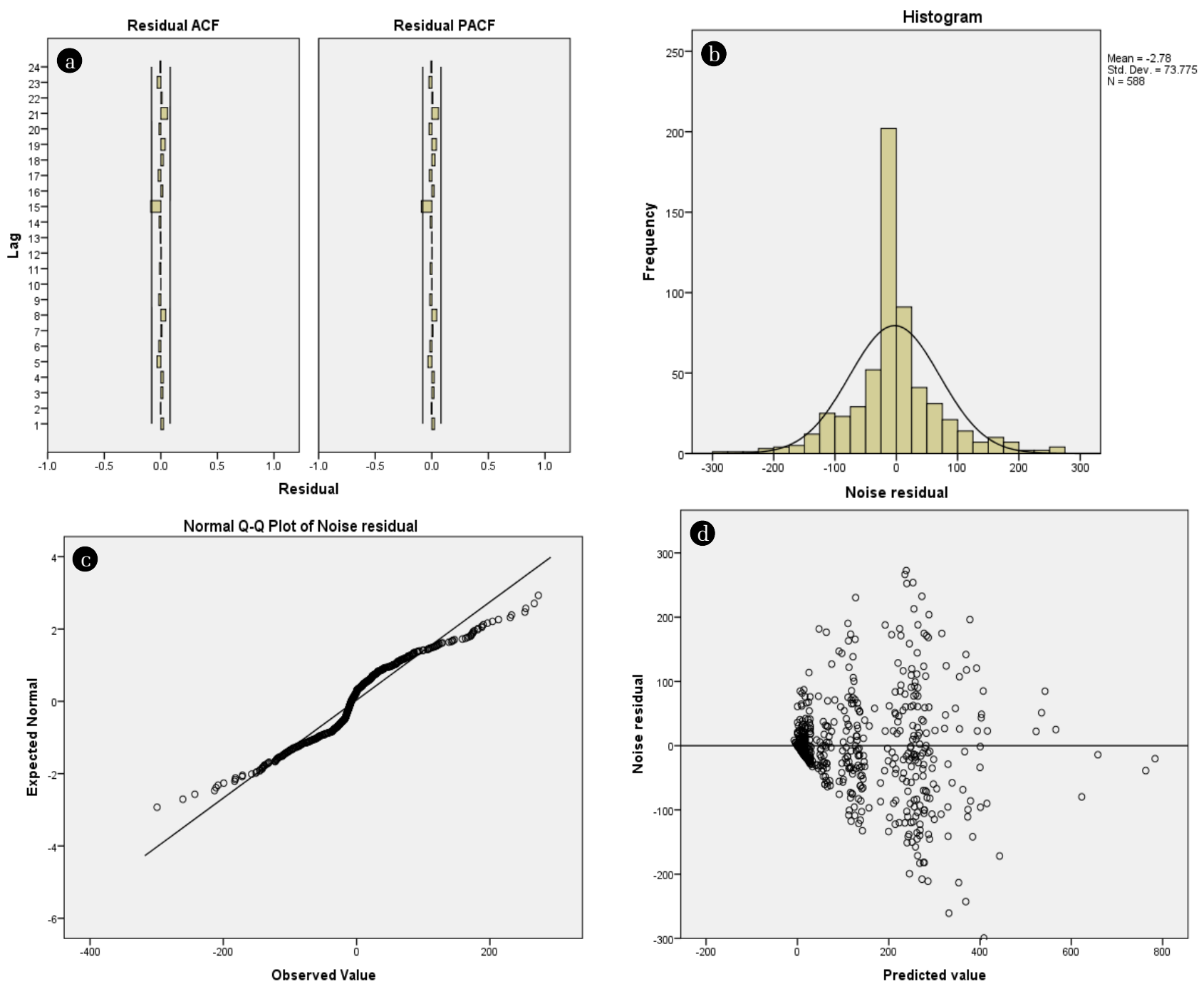

Fig. 4. Diagnostic check for best fitted model for rainfall series of Rajshahi.

as a straight line when plotted on normal probability paper [18]. The normal probability plot of residuals were found fairly linear for all stations, indicating the residuals are normally distributed. Fig. 4(c) represents the normal probability of residuals for Rajshahi station.

\subsubsection{Residuals versus prediction}

Residuals were plotted against predicted values. The plot (Fig. 4(d)) for Rajshahi station shows that residuals are evenly distributed around mean, which indicate that the model is well fitted. Similar results were found for other stations also.

\subsubsection{Lack of fit test}

The modified Ljung Box statistics was used to verify the null hypothesis that the model is correctly specified [19]. The test statistics is shown in Table 2. The associated P-value is greater than 0.05 for maximum stations, which hold the null hypothesis of being white noise. The test indicates the models are adequate.

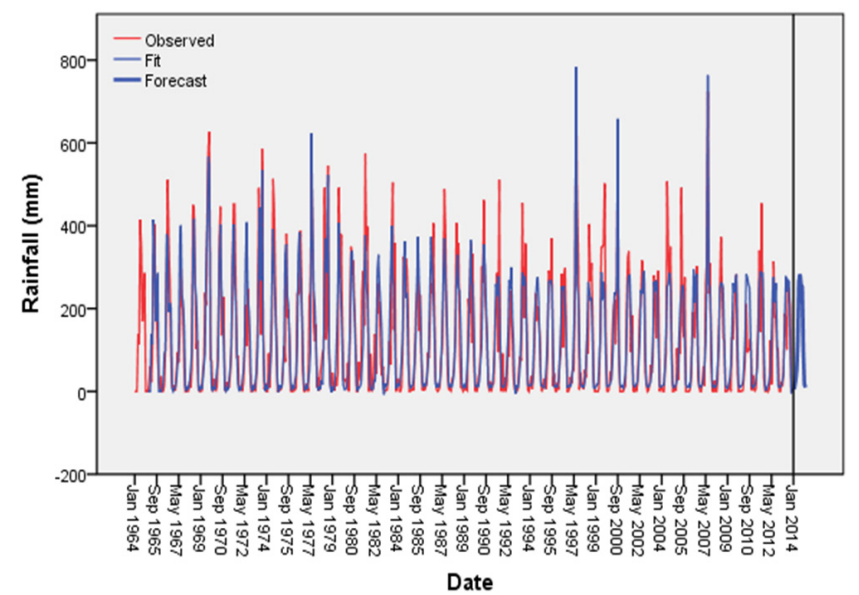

Fig. 5. Comparison of observed data with predicted data using best ARIMA model (Rajshahis). 
Table 2. Performance Criteria of Selected SARIMA Model

\begin{tabular}{|c|c|c|c|c|c|c|c|}
\hline \multirow[b]{2}{*}{ Station } & \multirow[b]{2}{*}{ Model } & \multicolumn{3}{|c|}{ Model Fit statistics } & \multicolumn{3}{|c|}{ Ljung-Box Q(18) } \\
\hline & & R-squared & RMSE & Normalized BIC & Statistics & $\begin{array}{c}\text { DF } \\
\text { (Degree of freedom) }\end{array}$ & Sig. \\
\hline Barishal & $\operatorname{ARIMA}(0,0,0)(0,1,1)$ & 0.672 & 104.2 & 9.3 & 21.1 & 17 & 0.221 \\
\hline Bhola & $\operatorname{ARIMA}(0,0,0)(0,1,1)$ & 0.708 & 108.9 & 9.4 & 18.0 & 17 & 0.386 \\
\hline Bogra & $\operatorname{ARIMA}(0,0,0)(0,1,1)$ & 0.765 & 81.60 & 8.9 & 20.6 & 17 & 0.241 \\
\hline Chandpur & $\operatorname{ARIMA}(0,0,0)(0,1,1)$ & 0.728 & 99.80 & 9.3 & 9.5 & 17 & 0.921 \\
\hline Chittagong & $\operatorname{ARIMA}(0,0,0)(0,1,1)$ & 0.735 & 147.4 & 10.0 & 10.8 & 17 & 0.862 \\
\hline Comilla & $\operatorname{ARIMA}(0,0,0)(0,1,1)$ & 0.680 & 104.2 & 9.3 & 12.9 & 17 & 0.742 \\
\hline Cox’s Bazar & $\operatorname{ARIMA}(0,0,0)(0,1,1)$ & 0.813 & 164.4 & 10.3 & 6.2 & 17 & 0.992 \\
\hline Dhaka & $\operatorname{ARIMA}(0,0,0)(1,1,2)$ & 0.720 & 93.20 & 9.2 & 11.0 & 15 & 0.749 \\
\hline Dinajpur & $\operatorname{ARIMA}(0,0,0)(0,1,1)$ & 0.800 & 85.90 & 9.0 & 27.6 & 17 & 0.049 \\
\hline Faridpur & $\operatorname{ARIMA}(0,0,0)(0,1,1)$ & 0.704 & 84.60 & 8.9 & 12.5 & 17 & 0.763 \\
\hline Hatiya & $\operatorname{ARIMA}(0,0,1)(0,1,1)$ & 0.832 & 120.6 & 9.7 & 20.2 & 16 & 0.209 \\
\hline Ishurdi & $\operatorname{ARIMA}(0,0,0)(0,1,1)$ & 0.787 & 70.50 & 8.7 & 18.7 & 17 & 0.342 \\
\hline Jessore & $\operatorname{ARIMA}(0,0,0)(0,1,2)$ & 0.730 & 78.20 & 8.8 & 11.7 & 16 & 0.76 \\
\hline Khepupara & $\operatorname{ARIMA}(0,0,1)(0,1,1)$ & 0.762 & 123.2 & 9.7 & 18.9 & 16 & 0.271 \\
\hline Khulna & $\operatorname{ARIMA}(0,0,0)(0,1,1)$ & 0.716 & 85.30 & 8.9 & 20.6 & 17 & 0.243 \\
\hline Kutubdia & $\operatorname{ARIMA}(0,0,0)(0,1,1)$ & 0.792 & 146.2 & 10.1 & 3.4 & 17 & 0.96 \\
\hline Madaripur & $\operatorname{ARIMA}(0,0,0)(0,1,1)$ & 0.707 & 91.30 & 9.1 & 8.3 & 17 & 0.96 \\
\hline Maijdeecourt & $\operatorname{ARIMA}(0,0,0)(0,1,1)$ & 0.799 & 131.5 & 9.8 & 23.8 & 17 & 0.124 \\
\hline Mongla & $\operatorname{ARIMA}(0,0,0)(0,1,2)$ & 0.771 & 82.30 & 8.9 & 10.4 & 16 & 0.844 \\
\hline Mymensingh & $\operatorname{ARIMA}(0,0,0)(0,1,1)$ & 0.729 & 105.2 & 9.4 & 18.8 & 17 & 0.337 \\
\hline Patuakhali & $\operatorname{ARIMA}(0,0,0)(0,1,1)$ & 0.720 & 124.5 & 9.7 & 15.1 & 17 & 0.588 \\
\hline Rajshahi & $\operatorname{ARIMA}(0,0,0)(1,1,1)$ & 0.741 & 74.40 & 8.7 & 9.0 & 16 & 0.911 \\
\hline Rangamati & $\operatorname{ARIMA}(0,0,0)(1,1,1)$ & 0.721 & 124.1 & 9.7 & 16.2 & 16 & 0.434 \\
\hline Rangpur & $\operatorname{ARIMA}(0,0,0)(0,1,1)$ & 0.763 & 100.1 & 9.3 & 4.6 & 17 & 0.999 \\
\hline Satkhira & $\operatorname{ARIMA}(0,0,0)(0,1,1)$ & 0.701 & 82.60 & 8.9 & 16.4 & 17 & 0.496 \\
\hline Shrimangal & $\operatorname{ARIMA}(0,0,0)(0,1,1)$ & 0.720 & 103.8 & 9.3 & 14.9 & 17 & 0.597 \\
\hline Sitakunda & $\operatorname{ARIMA}(0,0,0)(0,1,1)$ & 0.732 & 147.7 & 10.1 & 11.0 & 17 & 0.853 \\
\hline Sylhet & $\operatorname{ARIMA}(0,0,0)(0,1,2)$ & 0.750 & 169.3 & 10.3 & 7.1 & 16 & 0.971 \\
\hline Tangail & $\operatorname{ARIMA}(0,0,0)(0,1,1)$ & 0.761 & 82.40 & 9.04 & 17.5 & 17 & 0.414 \\
\hline Teknaf & $\operatorname{ARIMA}(0,0,0)(0,1,1)$ & 0.868 & 161.6 & 10.3 & 17.0 & 17 & 0.448 \\
\hline
\end{tabular}

\subsection{Rainfall Forecasting}

The forecast is done for 12 months lead time, using the best model calculated from historical data. The plot between observed and predicted values (Rajshahi station) in Fig. 5 indicates that the predicted values follow the observed data closely enough. The performance criteria of the selected seasonal ARIMA model are shown in Table 2. The high value of R-square indicates the performance of the model is fair enough. The appropriateness of the models is confirmed by investigating Normalized BIC. The models have least BIC value, upheld the significance of the model. In addition to statistical terms, the performance of the developed models was compared with the available literature in the country (e.g. Bari et al. 2015 and Mahsin et al. 2012) and found sound in rainfall forecasting comparing to these.

\section{Conclusions}

Rainfall forecast becomes difficult in Bangladesh due to its non-linear pattern and the spatiotemporal variation in size. However, prediction of rainfall is necessary for flood management, rainwater harvesting, urban planning, water resource management, planning and optimal operation of the irrigation system. Considering the significance, rainfall forecasting using widely accepted ARIMA modeling technique is done in this paper. The highest R-squared value (0.868) was found for Teknaf station and the lowest value (0.672) was found for the Barishal station. Only two stations contain R-squared value below 0.70 which indicate the SARIMA models developed to forecast rainfall in the present study is reasonably precise. Hence, these SARIMA models can be used as a convenient tool for nationwide rainfall forecasting. 


\section{References}

1. Box GE, Jenkins GM. Time series analysis: Forecasting and control. Rev. ed. San Francisco: Holden-Day; 1976.

2. Mishra AK, Desai VR. Drought forecasting using stochastic models. Stoch. Environ. Res Ris. Assess. 2005;19:326-339.

3. Rahman M, Islam AHMS, Nadvi SYM, Rahman RM. Comparative study of ANFIS and ARIMA model for weather forecasting in Dhaka. Informatics, Electronics \& Vision (ICIEV), 2013 International Conference on, Dhaka; 2013. p. 1-6.

4. Johnson LA, Montgomery DC. Forecasting and time series analysis. New York: McGraw-Hill; 1976.

5. Dizon CQ. ARMA modeling of a stochastic process appropriate for the angat reservoir. Philipp. Eng. J. 2007;28:1-20.

6. Momani PENM. Time series analysis model for rainfall data in Jordan: Case study for using time series analysis. Am. J. Environ. Sci. 2009;5:599-604.

7. Mahsin M, Akhter Y, Begum M. Modeling rainfall in Dhaka division of Bangladesh using time series analysis. J. Math. Model. Appl. 2012;1:67-73.

8. Bari SH, Rahman MT, Hussain MM, Ray S. Forecasting monthly precipitation in Sylhet city using ARIMA model. Civil Environ. Res. 2015;7:69-77.

9. Rashid HE. Geography of Bangladesh. 2nd ed. Dhaka: Univ. Press Ltd.; 1991. p. 545.

10. Shahid S. Rainfall variability and the trends of wet and dry periods in Bangladesh. Int. J. Climatol. 2010;30:2299-2313.

11. You Q, Kang S, Aguilar E, Yan Y. Changes in daily climate extremes in the eastern and central Tibetan Plateau during 1961-2005. J. Geophys. Res-Atmos. 2008;113:D07101.

12. Mortuza MR, Selmi S, Khudri MM, Ankur AK, Rahman MM. Evaluation of temporal and spatial trends in relative humidity and dew point temperature in Bangladesh. Arab. J Geosci. 2014;7:5037-5050.

13. Alexandersson $\mathrm{H}$. A homogeneity test applied to precipitation data. J. Climatol. 1986;6:661-675.

14. Von Neumann J. Distribution of the ratio of the mean square successive difference to the variance. Ann. Math. Statist. 1941;12:367-395.

15. Buishand TA. The analysis of homogeneity of long-term rainfall records in the Netherlands. KNMI Scientific Report WR 81-7, De Bilt, The Netherlands; 1981.

16. Pettitt AN. A non-parametric approach to the change-point problem. J. Roy. Stat. Soc. C-App. 1979;28:126-135.

17. Box G, Jenkins G, Reinsel G. Time series analysis: Forecasting \& control [Internet]. 3rd ed. New Jersy: Prentice Hall; c1994 [cited 23 February 2016]. Available from: http://www.amazon.ca/exec/obidos/redirect?tag $=$ citeulike09-20\&path $=$ ASIN/0130607746.

18. Chow VT, Maidment DR, Mays LW. Applied hydrology [Internet]. New York: Mcgraw-Hill Book Company; c1988 [cited 23 February 2016]. Available from: http://documentatiecentrum. watlab.be/imis.php?module $=$ ref\&refid $=127685 \&$ basketaction =add.

19. Ljung GM, Box GEP. On a measure of lack of fit in time series models. Biometrika 1978;65:297-303. 